This work is licensed under a Creative Commons Attribution 3.0 License.

\title{
A new Oriental genus of bostrichid beetle (Coleoptera: Bostrichidae: Xyloperthini), a new synonym and a lectotype designation for Octodesmus episternalis (Lesne, 1901)
}

\author{
Lan-Yu LIU ${ }^{1, *}$, Roger A. BEAVER ${ }^{2} \&$ Sunisa SANGUANSUB ${ }^{3}$ \\ ${ }^{1}$ Department of Science Communication, National Pingtung University, No.4-18, Minsheng Rd, \\ Pingtung City, Pingtung County 90049, Taiwan. \\ ${ }^{2} 161 / 2 \mathrm{Mu}$ 5, Soi Wat Pranon, T. Donkaew, A. Maerim, Chiangmai 50180, Thailand. \\ ${ }^{3}$ Department of Entomology, Faculty of Agriculture at Kamphaeng Saen, Kasetsart University, \\ Kamphaeng Saen, Nakhonpathom 73140, Thailand. \\ "Corresponding author: liulysky@gmail.com \\ 2 rogerbeaver6@gmail.com \\ 33agrssss@ku.ac.th \\ ${ }^{1}$ urn:1sid:zoobank.org:author:8A4ECE7C-2607-440D-B1BC-6E3B05EF02BB \\ 2 urn:1sid:zoobank.org:author:EEF5C471-ECFB-4786-8E2F-13C5B5EC4F0D \\ ${ }^{3}$ urn:1sid:zoobank.org:author:65EBEA67-515A-4CC7-AE93-DAD47765971E
}

\begin{abstract}
A new genus and species of bostrichid beetle, Octomeristes gen. nov. and Octomeristes pusillus gen. et sp. nov., in the tribe Xyloperthini is described from litchi (Litchi chinensis Sonn.) wood in Thailand. The genus is compared to Octodesmus Lesne, 1901, the only other xyloperthine genus with eight-segmented antennae, and to the xyloperthine genera, Xylion Lesne, 1901, Xylionulus Lesne, 1901 and Xylobosca Lesne, 1901. A new combination, Octomeristes minutissimus (Lesne, 1932) comb. nov., is transferred from Octodesmus Lesne, 1901. A lectotype is designated for Octodesmus episternalis Lesne, 1901, the type species of Octodesmus. Octodesmus kamoli Chûjô, 1964 is designated a new synonym of Paraxylion bifer (Lesne, 1932). A key is provided to the species of Octodesmus and Octomeristes gen. nov.
\end{abstract}

Key words. Octomeristes gen. nov., Octodesmus, Paraxylion, lectotype, new synonymy.

Liu L.-Y., Beaver R.A. \& Sanguansub S. 2016. A new Oriental genus of bostrichid beetle (Coleoptera: Bostrichidae: Xyloperthini), a new synonym and a lectotype designation for Octodesmus episternalis (Lesne, 1901). European Journal of Taxonomy 189: 1-12. http://dx.doi.org/10.5852/ejt.2016.189

\section{Introduction}

The family Bostrichidae, the bostrichid beetles, can be divided into nine subfamilies (Borowski \& Węgrzynowicz 2007; Liu \& Schönitzer 2011), of which the largest is the Bostrichinae. The Bostrichinae comprises three tribes, of which the most genus-rich is the Xyloperthini with 33 genera (Borowski \& Węgrzynowicz 2007; Park et al. 2015). The tribe is characterized by the lamelliform intercoxal process of the first abdominal ventrite, which is visible only as a narrow carina and does not have a ventral face, 
and by the mandibles crossing at their tips (Lesne 1921; Fisher 1950; Liu \& Schönitzer 2011). The tribe has a worldwide distribution, but the individual genera are mostly confined to a single zoogeographical region or subregion (Borowski \& Węgrzynowicz 2007). There is little information available on the biology of the majority of xyloperthine species, probably because they are not major, economically important pests. A few species have been studied by Beeson \& Bhatia (1937) and Liu et al. (2008). The adults are polyphagous, usually attacking a taxonomically wide variety of host trees. They bore into twigs and branches, where they construct a short gallery, usually consisting of a circumferential and one or more longitudinal branches (Liu et al. 2008) in which the eggs are laid. The larvae bore through the wood making extensive galleries filled with fine wood particles and excreta. The new generation of adults emerges through the bark, but may reattack the same stem, so that the whole of the sapwood is eventually converted into fine powder (Liu et al. 2008). The development time is variable depending on local conditions, and may vary from a few weeks to over a year (Beeson \& Bhatia 1937).

Here, we describe a new genus and species of xyloperthine bostrichid beetle from Thailand. The new genus is compared with Octodesmus Lesne, 1901, the only other xyloperthine genus with eightsegmented antennae, and with the possibly related xyloperthine genera, Xylobosca Lesne, 1901, Xylion Lesne, 1901 and Xylionulus Lesne, 1901. Octodesmus minutissimus Lesne, 1932 is transferred to the new genus. A lectotype is designated for Octodesmus episternalis Lesne, 1901. Octodesmus kamoli Chûjô, 1964 is designated a new synonym of Paraxylion bifer (Lesne, 1932). A key is provided to distinguish the species of Octodesmus and Octomeristes gen. nov.

\section{Material and methods}

Specimens of the new genus and species were collected by the junior author (SS) during the course of studies of the wood-boring beetles attacking fruit trees in Thailand. Its generic status has been ascertained from studies by the senior author (LYL) of all available xyloperthine types, and other specimens, in the Paris Museum (MNHN) and other major European museums, and the Kyushu University Museum, Japan. We have examined type material or reliably identified specimens of 30 out of 33 previously described genera of Xyloperthini, and have checked the descriptions of the remaining 3 genera. We have also examined specimens in the private collections of LYL and RAB.

The following abbreviations are used for Museums and other collections:

$\mathrm{KSU}=$ Entomology Department, Kasetsart University, Kamphaeng Saen

KUM = Entomological Laboratory, Faculty of Agriculture, Kyushu University, Fukuoka

LYL = Private collection of Liu Lan-Yu, Yilan

MNHN = Muséum national d'Histoire naturelle, Paris

NHML $=$ Natural History Museum, London

QSBG = Entomology Division, Queen Sirikit Botanical Garden, Chiang Mai

$\mathrm{RAB}=$ Private collection of Roger A. Beaver, Chiang Mai

Photographs were taken with a Nikon Coolpix 4500 digital camera, combined with the program CombineZP, and optimized with Adobe Photoshop CS2. 
LIU L.-Y. et al., A new genus of bostrichid beetle

\title{
Results
}

\author{
Superfamily Bostrichoidea Latreille, 1802 \\ Family Bostrichidae Latreille, 1802 \\ Subfamily Bostrichinae Latreille, 1802 \\ Tribe Xyloperthini Lesne, 1921 \\ Octomeristes Liu \& Beaver, gen. nov. \\ urn:lsid:zoobank.org:act:4D659D1D-561C-445C-A256-AFA66495D93C
}

\section{Type species}

Octomeristes pusillus Liu \& Beaver, gen. et sp. nov., here designated.

\section{Diagnosis}

A member of the tribe Xyloperthini, characterized by the lamelliform intercoxal process of the first abdominal ventrite, and the mandibles crossed at the tips (Lesne 1901; Fisher 1950; Liu \& Schönitzer 2011). Distinguished from other genera of Xyloperthini by the following combination of characters: Frons weakly convex, without a crown of hairs on the head in either sex. Mandibles symmetrical, sharply pointed; antenna with eight antennomeres, the funicle and club each trimerous, antennomeres of club lacking stiff, erect hairs, with two indistinct c-shaped sensory impressions near the apex of antennomeres 6 and 7, but not on the last antennomere; pronotum without a lateral carina; posterior part of elytral disc with more than one pair of costae, each ending in a small process at the upper margin of the elytral declivity; protibiae normal, without small teeth on posterior face; female with third abdominal ventrite projecting over and concealing fourth ventrite, its posterior margin with lobes or teeth; fifth abdominal ventrite of male with pleural pieces.

\section{Etymology}

The genus name is masculine, and refers to the eight-segmented antenna.

\section{Description}

Body elongate, cylindrical. Head deeply inserted in prothorax, not visible from above. Frons convex or slightly impressed, with scattered, fine, upwardly-directed hairs, which are denser and coarser laterally; fronto-clypeal suture indistinct at sides, impressed in middle; clypeus strongly transverse, anterior margin with a very short median lobe or projection, an emargination on each side of the lobe; labrum transverse with a fringe of hairs along anterior margin. Mandibles subequal, sharply pointed. Eyes small, oval, globose, strongly projecting. Antenna with 8 antennomeres, first antennomere elongate, about twice as long as the oval second, antennomeres 3-5 forming a loose funicle, each antennomere short, strongly transverse, the fifth widest, together slightly shorter than second antennomere; antennomeres 6-8 forming the elongate, compressed club, each antennomere with a dense covering of short, recumbent hairs, two indistinct c-shaped sensory impressions on the surface of antennomeres 6 and 7 near apex, but absent from antennomere 8; antennomeres 6 and 7 subquadrate to subtriangular, subequal in length, last antennomere elongate, oval, length variable from 1.5-1.9 times longer than the previous antennomere, but subequal in width.

Pronotum slightly wider than long, widest about one-third from base, anterior angles with a strong, upcurved tooth on margin, anterior margin between teeth straight, not depressed behind the margin; semicircular area above the anterior margin smooth and without teeth; sides broadly rounded, converging more strongly anteriorly, posterior angles broadly rounded, without a lateral carina, postero-lateral area with fine rugulosities; disc smooth, shining, very indistinctly punctured, glabrous; anterior slope with 3 or 4 large, upcurved teeth antero-laterally on each side behind the marginal tooth, with short, semi-erect hairs between the teeth. 


\begin{tabular}{|c|c|c|c|c|c|c|c|c|c|c|c|c|}
\hline 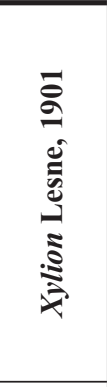 & 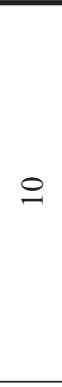 & 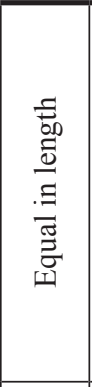 & 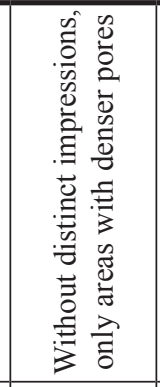 & 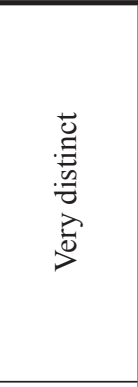 & 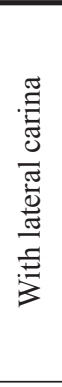 & 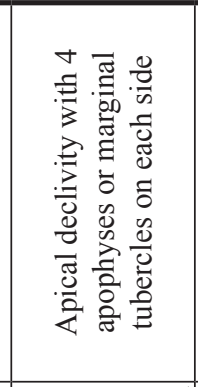 & 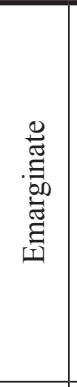 & 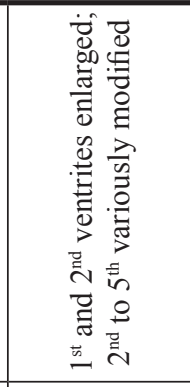 & 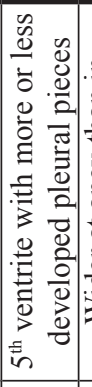 & 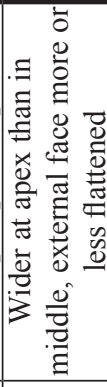 & 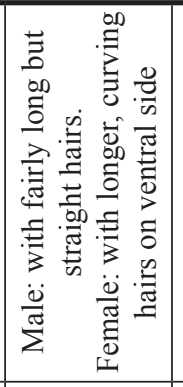 & 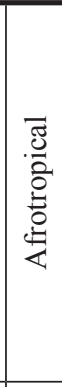 \\
\hline 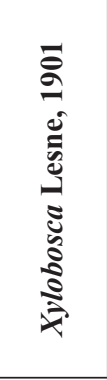 & 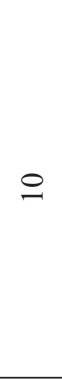 & 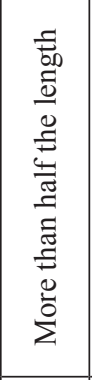 & 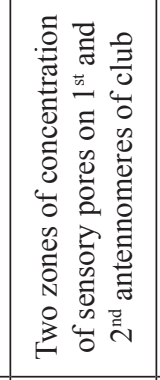 & 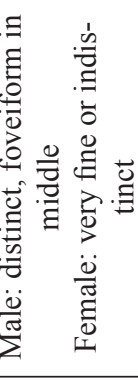 & 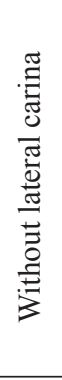 & 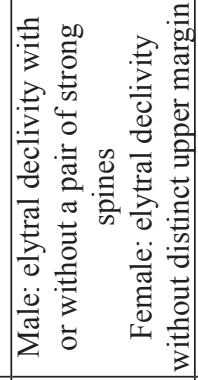 & 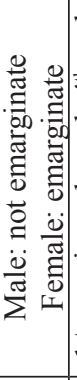 & 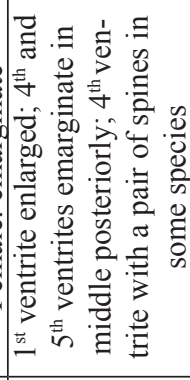 & 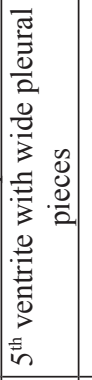 & 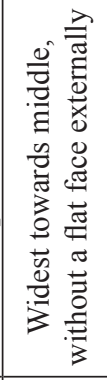 & 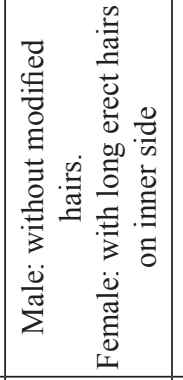 & \\
\hline 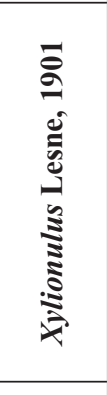 & 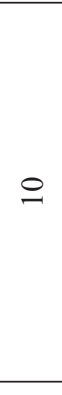 & 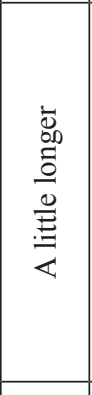 & 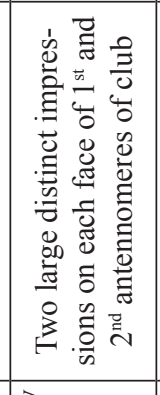 & 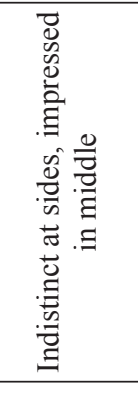 & 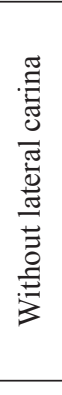 & 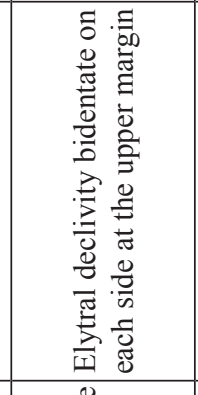 & 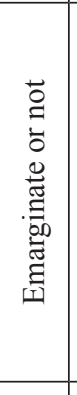 & 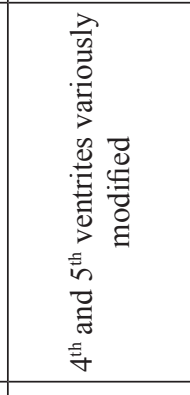 & 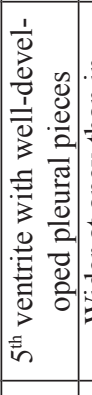 & 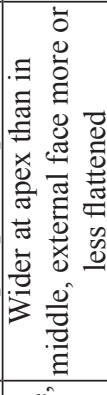 & 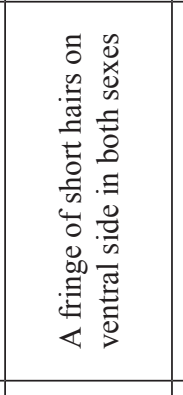 & 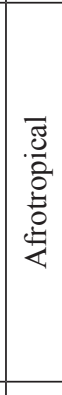 \\
\hline 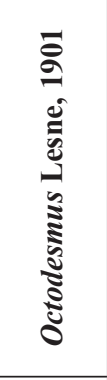 & $\infty$ & 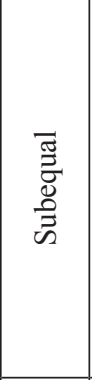 & 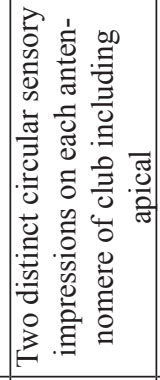 & 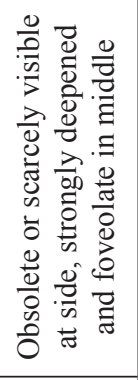 & 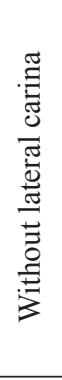 & 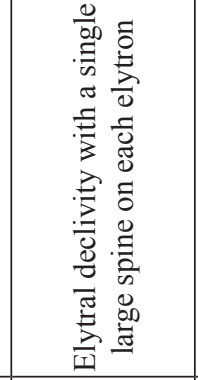 & 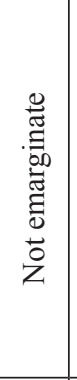 & 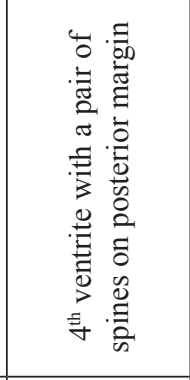 & 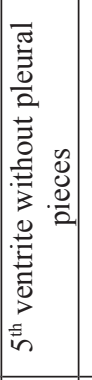 & 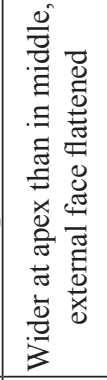 & 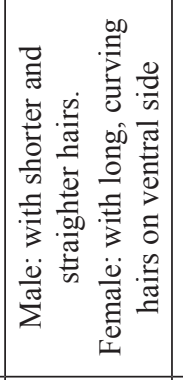 & 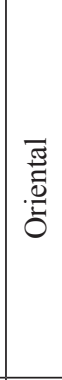 \\
\hline 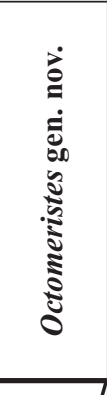 & $\infty$ & 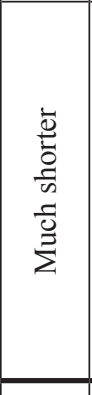 & 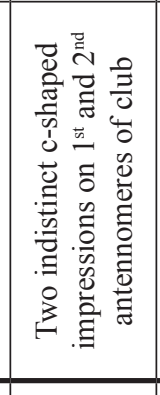 & 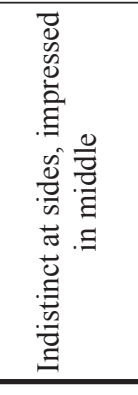 & 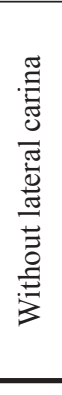 & 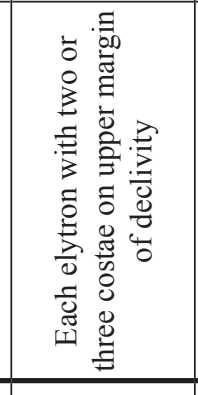 & 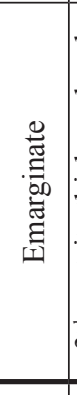 & 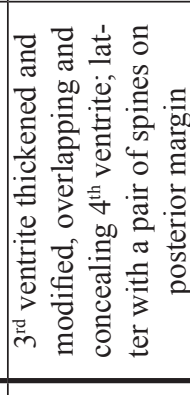 & 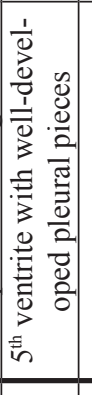 & 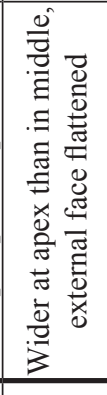 & 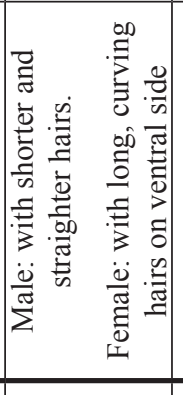 & 嵒 \\
\hline / & 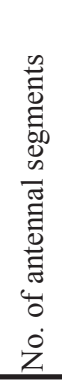 & 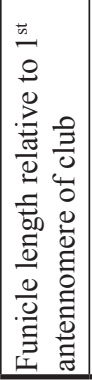 & 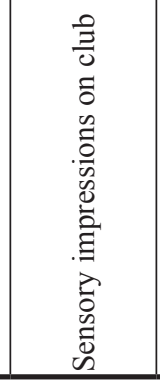 & 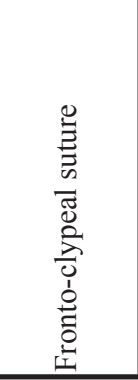 & 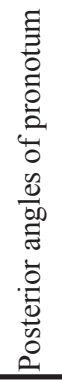 & 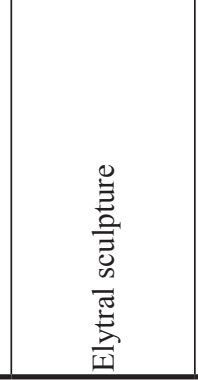 & 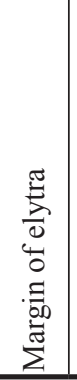 & 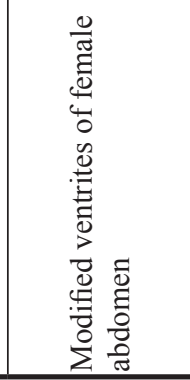 & 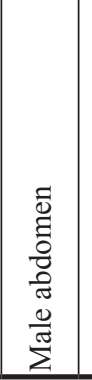 & 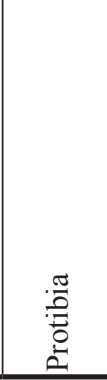 & 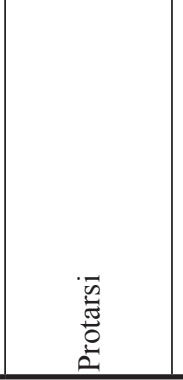 & 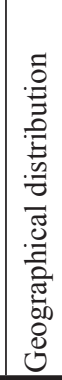 \\
\hline
\end{tabular}


LIU L.-Y. et al., A new genus of bostrichid beetle

Scutellum, small, punctate. Elytra subequal to pronotum in width, strongly convex, smooth, shining, indistinctly punctured anteriorly, the punctures larger and deeper near the declivity, posterior part of disc with more than one pair of costae, each costa ending in a small tooth or projection at upper margin of declivity; declivity weakly convex, glabrous, the postero-lateral margin emarginate.

Legs subequal in length, procoxae contiguous, mesocoxae narrowly separated; tibiae expanded toward apices, protarsi equal in length to protibiae, meso- and meta-tarsi longer than their respective tibiae.

Intercoxal process of first abdominal ventrite lamelliform. Female with third abdominal ventrite projecting over and concealing fourth ventrite, its posterior margin with lobes or teeth. Last visible abdominal ventrite of male with pleural pieces.

\section{Remarks}

The genus Octomeristes gen. nov. (abbreviated here as $\mathrm{Om}$.) is noteworthy because the antennae have only eight segments. The only other genus of Xyloperthini with 8-segmented antennae is Octodesmus Lesne (abbreviated here as $O d$.). Other xyloperthine genera have 9- to 11-segmented antennae. There are presently four species in Octodesmus: the type species, Od. episternalis (Lesne, 1901), Od. parvulus (Lesne, 1897), Od. minutissimus (Lesne, 1932) and Od. kamoli Chûjô, 1964 (Borowski \& Wegrzynowicz 2007). The senior author has examined syntypes of Od. episternalis (MNHN), the holotype of Od. parvulus (MNHN), and the holotype of Od.kamoli (KUM). We have been unable to examine type material of Od. minutissimus. However, it has been possible to show (see discussion below) that it should be transferred to Octomeristes gen. nov., and it is considered here as a member of that genus. When Lesne (1932) described Octodesmus minutissimus, he suggested that it formed a link between Octodesmus on the one hand, and the genera Xylion Lesne, 1901, Xylionulus Lesne, 1901 and Xylobosca Lesne, 1901 on the other. Since then, the genus Xylion has been split up (Lesne 1940; Vrydagh 1955), and the genus restricted to a more closely related group of seven species (Vrydagh 1955). Following Lesne's (1932) suggestion, we compare Octomeristes gen. nov. (including Om. minutissimus comb. nov.) to the four genera listed by him, using Xylion in the restricted sense of Vrydagh (1955) (Table 1). A more wide-ranging study of the genera of Xyloperthini would be valuable, but is beyond the scope of the present paper.

The genus Octomeristes gen. nov. can be distinguished from all other xyloperthine genera by the combination of the 8-segmented antenna, with the funicle length much shorter than the first antennomere of the antennal club, and the thickened and modified third abdominal ventrite, which overlaps and conceals the fourth ventrite. Octomeristes gen. nov. is further distinguished from Octodesmus by the absence of sensory impressions on the apical segment of the antennal club (present in Octodesmus), the sculpture of the elytra (Table 1), and the presence in the male of well-developed pleural pieces (absent in Octodesmus). It is likely that the reduction in the number of antennal segments in the two genera is related to the small size of the species, and is not an indication of a close relationship. Xylion, Xylionulus and Xylobosca all have 10-segmented antennae.

The genus Xylobosca is distinguished from Octomeristes gen. nov. and the other genera considered here by the form of the protibia, which is atypical for the Xyloperthini, and is widest towards the middle (not at the apex), and lacks a flat external face. The sexual dimorphism of the elytra of Xylobosca is also quite different from Octomeristes gen. nov. However, it is interesting to note the presence of a pair of spines on the fourth ventrite of the female in some species of Xylobosca, as in Octomeristes gen. nov. The genus Xylion is distinguished from Octomeristes gen. nov. and the other three genera by the presence of a lateral carina at the posterior angles of the pronotum, and the remarkable enlargement and modification of the second abdominal ventrite of the female.

The genus that is morphologically most similar to Octomeristes gen. nov. is Xylionulus, with very similar characters of the frons, pronotum and elytra (Table 1). However, the two genera can be distinguished by 
characters of the antennae (Table 1), and the modification of the fourth and fifth ventrites of the female abdomen in Xylionulus and not the third ventrite.

Xylion and Xylionulus are Afrotropical genera, Xylobosca is an Australian genus, whilst Octodesmus and Octomeristes gen. nov. are Oriental genera, but the morphological similarities of the five genera might indicate a common origin in Gondwana.

\section{Distribution}

India, northern Thailand.

Octomeristes pusillus Liu \& Beaver, gen. et sp. nov. urn:1sid:zoobank.org:act:49448B21-C6F2-4868-A919-F350D93E89B8

Figs 1-3

\section{Etymology}

The species name refers to the diminutive size of the beetle, which is one of the smallest species of Bostrichidae.

\section{Type material}

\section{Holotype}

THAILAND: 1 (NHML[E]/2013-96), "Chiang Mai, Doi Pui, Khun Chang Highland Research Station. c. 1300m, ex Litchi chinensis, 18.v.2013 (S. Sanguansub)".
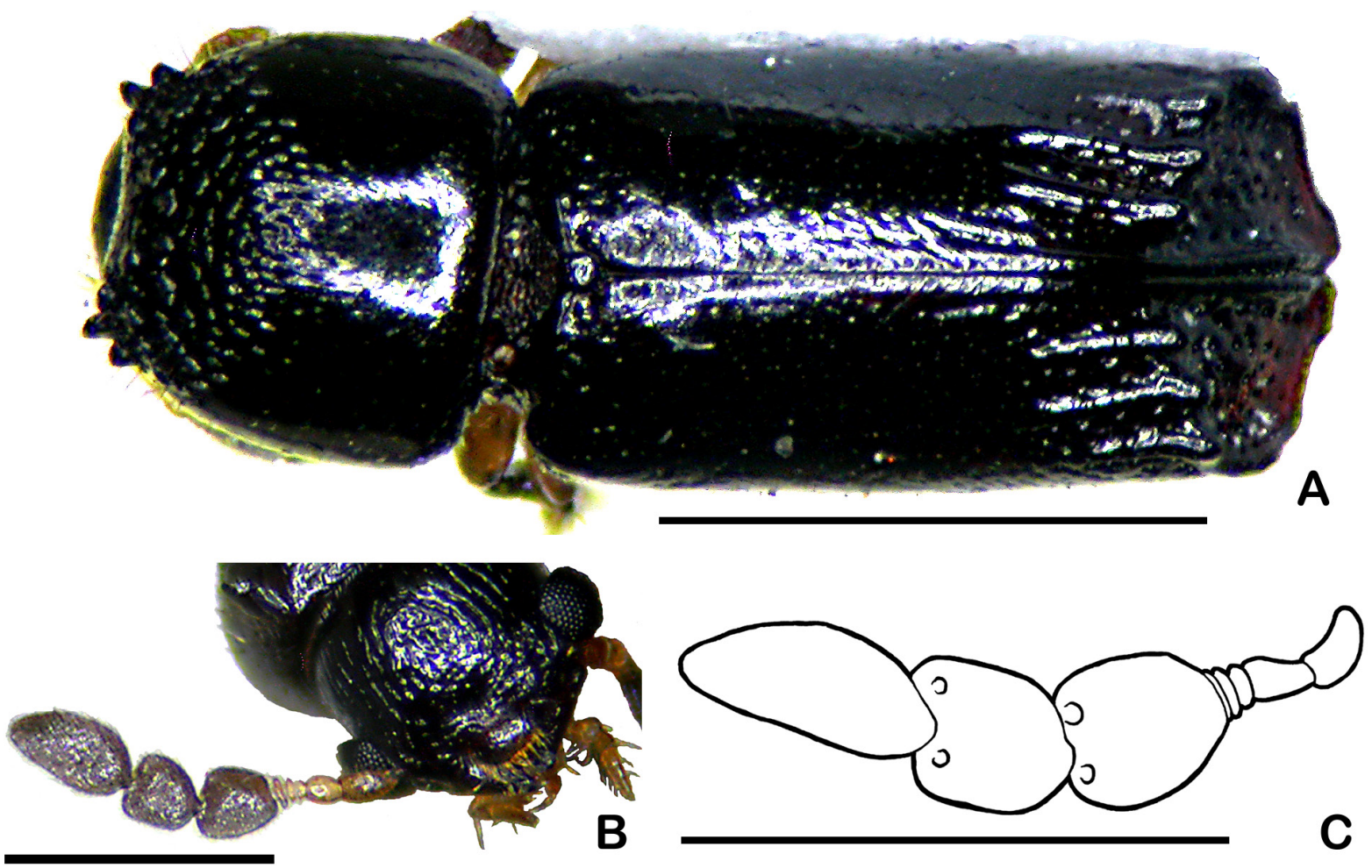

Fig. 1. Octomeristes pusillus Liu \& Beaver, gen. et sp. nov., paratype (LYL). A. Dorsal view. B. Front view of head and right antenna. C. Antenna showing position of impressed sensory areas on $6^{\text {th }}$ and $7^{\text {th }}$ antennomeres. Scale bars: $\mathrm{A}=1 \mathrm{~mm} ; \mathrm{B}-\mathrm{C}=0.5 \mathrm{~mm}$. 
LIU L.-Y. et al., A new genus of bostrichid beetle

\section{Allotype}

THAILAND: $1 \lesssim$ (NHML[E]/2013-96), same data as for the holotype.

\section{Paratypes}

THAILAND: 1 , $1 \lesssim(\mathrm{RAB})$, same data as for the holotype; 2 우 (LYL), same data as for the holotype; THAILAND: $1 \hat{\jmath}$ (KSU), same data as for the holotype; $1 \hat{\jmath}$ (damaged, QSBG), "Nan, Doi Phu Kha NP, Office $14,19^{\circ} 12.488$ 'N, $101^{\circ} 4.907^{\prime} \mathrm{E}, 1375 \mathrm{~m}$, pan trap, 2-3.xii.2007 (Charoen \& Nikhom)".

\section{Description}

Body 1.9-2.1 mm long, about 2.7 times (male) or 2.8 times (female) as long as wide, cylindrical; piceous, shining, labrum brown, palps, first five antennomeres and legs pale yellowish or yellowishbrown, except for blackish anterior tibiae. Frons convex, almost smooth and finely punctured in middle, towards sides a series of long, concentrically arranged, fine rugae extending to vertex (Fig. 1B),

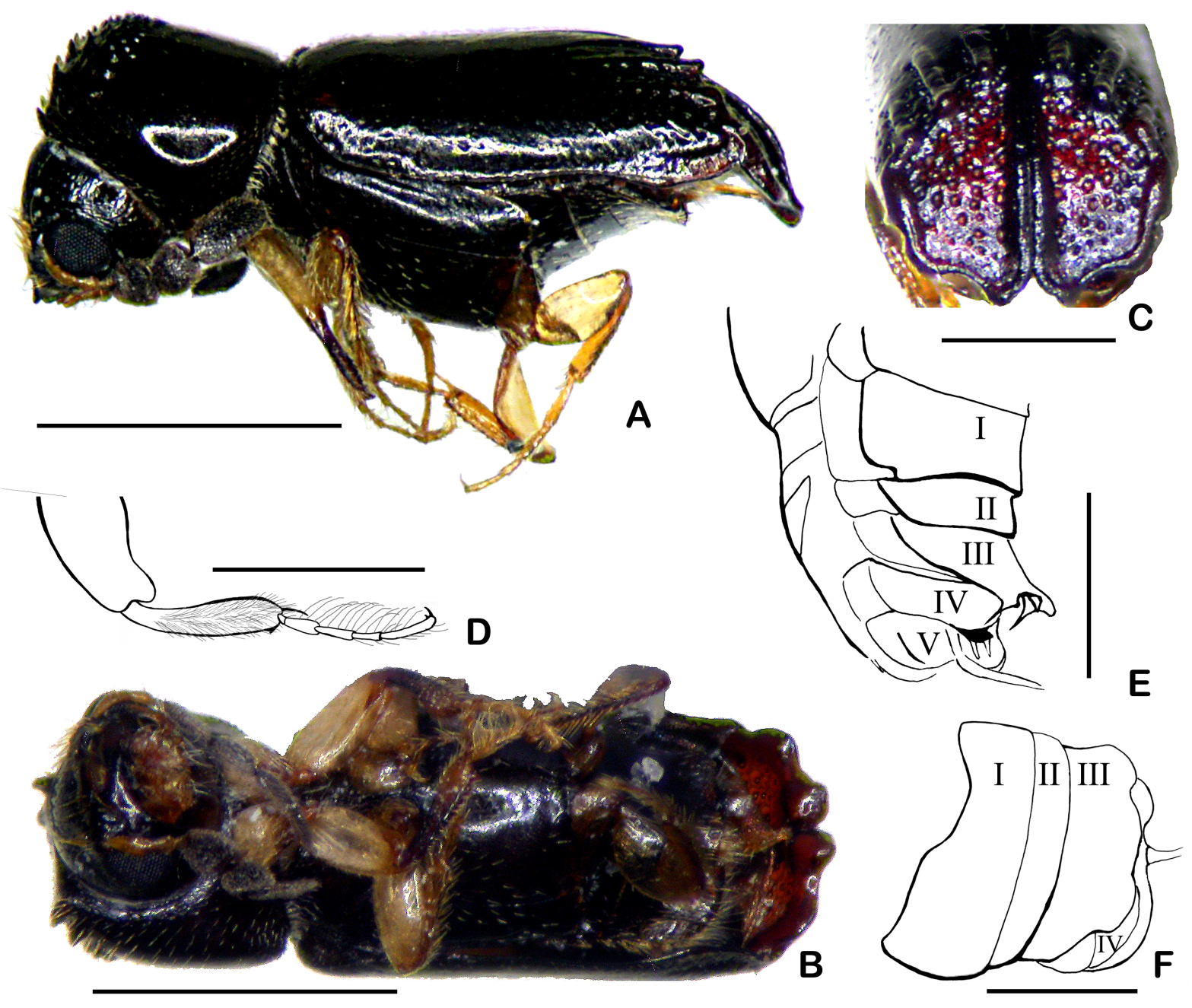

Fig. 2. Octomeristes pusillus Liu \& Beaver, gen. et sp. nov., paratype, $q$ (LYL). A. Lateral view. B. Ventral view. C. Posterior view of elytral declivity. D. Proleg showing long, curling hairs on ventral side of tarsi and dense, fine hairs on inner face of tibia. E. Latero-ventral view of abdomen showing modified $3^{\text {rd }}$ to $5^{\text {th }}$ ventrites. F. Ventral view of abdomen. Scale bars: A-B $=1 \mathrm{~mm} ; \mathrm{C}-\mathrm{F}=0.5 \mathrm{~mm}$ (in $\mathrm{E}-\mathrm{F}$ : I to $\mathrm{V}$ are the $1^{\text {st }}$ to $5^{\text {th }}$ ventrites, $\mathrm{O}$ is the ovipositor.). 
scattered, fine, upwardly-directed hairs denser, coarser and more erect near eyes and antennal insertions. Female with one extremely long hair on each side inserted close to eye. Fronto-clypeal suture indistinct at sides, impressed in middle. Clypeus slightly convex, granulate-punctate, depressed along posterior margin in median half, anterior margin with very short median lobe, weakly concave anteriorly, a small emargination on each side of lobe. Labrum transverse, a fringe of yellowish hairs along anterior margin. Antennae with a few erect hairs on inner and outer margins of first two antennomeres, a single hair on each side of antennomeres 3-5, antennomeres 6 and 7 subtriangular, subequal, eighth antennomere 1.8-1.9 times longer than antennomere 7, elongate-oval (Fig. 1B-C).

Pronotum 1.1-1.2 times wider than long, widest about one-third from base, anterior angles with a strong, upcurved tooth on margin, semicircular area above anterior margin with scattered, fine punctures; sides of pronotum broadly rounded, converging more strongly anteriorly, posterior angles broadly rounded, without lateral carina, postero-lateral area with fine rugulosities; anterior slope with 3-4 large upcurved teeth antero-laterally on each side, remaining teeth gradually reduced in size towards summit, and arranged approximately in arcs; discal surface smoooth and very indistinctly punctate on basal half, postero-lateral areas with small, widely-spaced, slightly elongate rugulosities. Anterior slope with short, semi-erect hairs between teeth, disc glabrous, small, recumbent hairs on sides.

Elytra about 1.8-1.9 times longer than wide, slightly more elongate in female than male, 2.2-2.3 times longer than pronotum, subequal to pronotum in width, sides parallel in female, slightly widened posteriorly in male; basal margin slightly convex, raised between humerus and scutellum, elytral disc

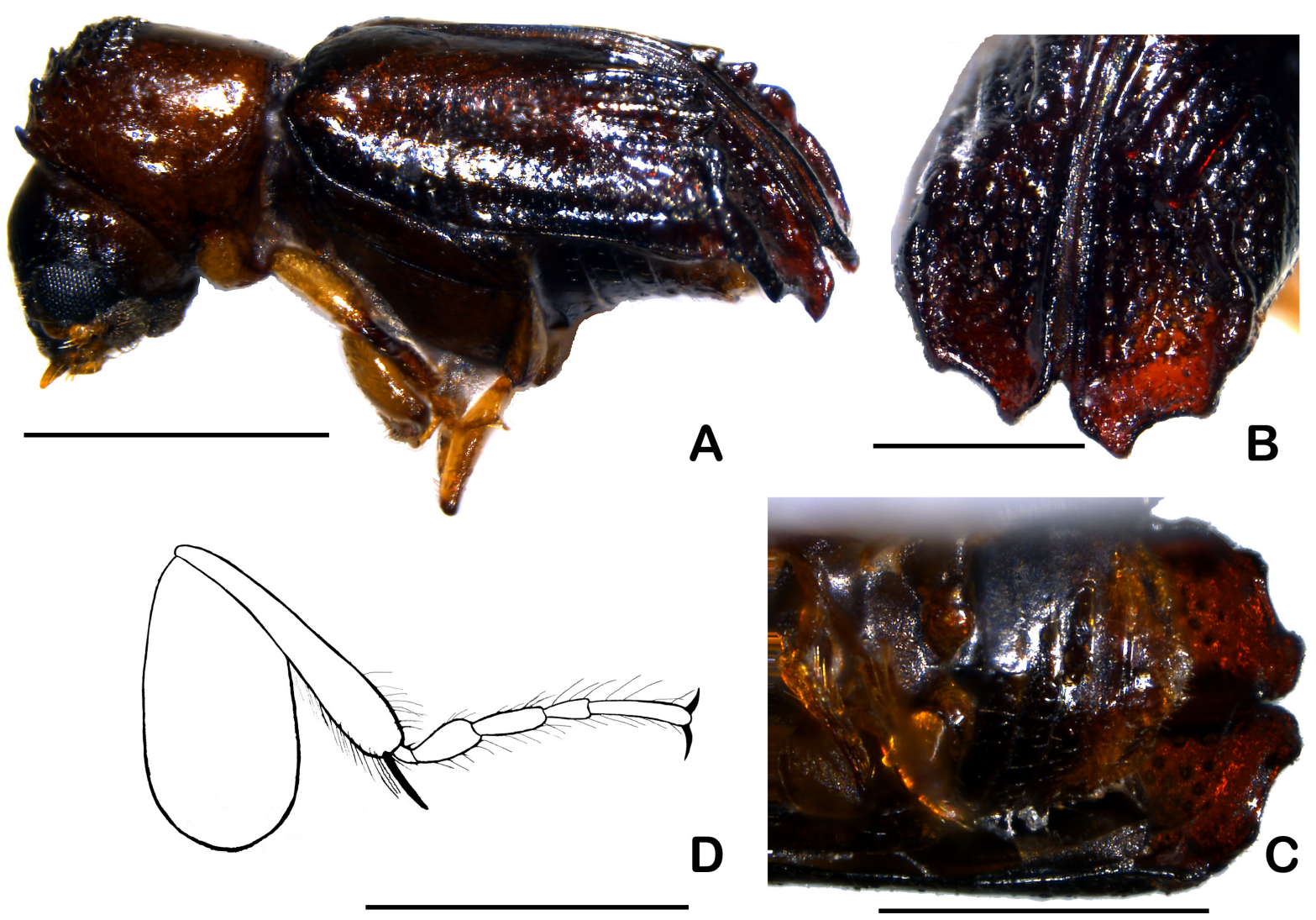

Fig. 3. Octomeristes pusillus Liu \& Beaver, gen. et sp. nov., paratype, $\widehat{o}$ (KSU). A. Lateral view. B. Postero-lateral view of elytral declivity. C. Ventral view of abdomen. D. Proleg showing short, straight hairs on tarsi. Scale bars: A $=1 \mathrm{~mm}$; B-D $=0.5 \mathrm{~mm}$. 
slightly depressed behind margin, basal two-thirds of disc extremely finely, sparsely punctured; posterior part of disc with three pairs of costae, slightly converging towards suture, costae and grooves between them with larger and deeper punctures, each costa ending in a small tooth with a rounded tip at upper margin of elytral declivity, tooth projecting slightly over declivity (Figs 1A; 2A, C); declivity weakly convex, glabrous, rather sparsely, shallowly, coarsely punctured, punctures decreasing in size and density toward apex; suture gradually more strongly raised from one-third from base, most strongly raised in middle of declivity; postero-lateral margin raised; elytral apex broadly rounded with a short, rounded projection on either side, a V-shaped emargination at the suture, and a shallow arcuate emargination lateral to apex (Figs 2C; 3B).

Legs subequal in length, tibiae expanded towards apex, a fringe of short hairs on outer margin, hairs shorter on protibiae; anterior surface of protibia flattened, matt, surface slightly roughened; apical spine of protibia longer in male than female. Inner face of female protibia with dense fine hairs (Fig. 2D). Protarsi of female with numerous, long, curling hairs on ventral side; male protarsi with shorter and straighter hairs (Figs 2D; 3D).

Female abdomen with first ventrite about 1.5 times as long as second, $3^{\text {rd }}$ ventrite about as long as $1^{\text {st }}$ and extending over $4^{\text {th }}$, concealing it, its apical third curved ventrally, apical margin thickened to form a projecting median lobe, and a larger rounded lobe at each side, thinner and depressed between these thickened areas. On dorsal surface of depressed areas on apex of $3^{\text {rd }}$ ventrite a pair of dorsally projecting spines, separated by width of median lobe. Apical margin of $4^{\text {th }}$ ventrite thickened to form a projecting median lobe, a pair of small spines extending posteriorly from each side of lobe. Apical margin of $5^{\text {th }}$ ventrite thickened at sides, a bunch of coarse hairs extending posteriorly from middle of apical margin (Figs 2B, E-F).

Male abdomen with first ventrite about 1.5 times as long as $2^{\text {nd. }} ; 2^{\text {nd }}, 3^{\text {rd }}$ and $4^{\text {th }}$ subequal, 5 th with welldeveloped pleural pieces. Surface of abdominal ventrites smooth, shining with sparse, recumbent hairs, a fringe of hairs on apical margin of $5^{\text {th }}$ ventrite (Fig. 3C).

\section{Distribution}

Northern Thailand.

Octomeristes minutissimus (Lesne, 1932) comb. nov.

Octodesmus minutissimus Lesne, 1932: 662.

Although Lesne (1932) deposited syntypes of Octodesmus minutissimus Lesne in MNHN, they can no longer be found (LYL, pers. obs. 2008; A. Taghavian, pers. comm. 2013). The remaining syntypes were deposited at the Forest Research Institute, Dehra Dun in India (Lesne 1932), and are unavailable for study. Specimens of this species could not be located in any of the fifteen major European museums visited by LYL, and none are in the large collection of M. Ivie (pers. comm. 2013). We have been unable to borrow specimens from India, the only country in which the species has been collected. However, we have been able to examine photographs of three specimens of Od. minutissimus in the National Pusa collection of the Indian Agricultural Research Institute, New Delhi. Unfortunately, the antennae of these specimens were missing or damaged, and we have no photograph of the ventral side of a female. However, we have been able to check other characters against the original description of Lesne (1932), and the redescription and figure of Rai (1971). It should be noted that there are some discrepancies between Rai's (1971) and Lesne's (1932) descriptions. In particular, Rai (1971) does not mention or figure the emarginations of the elytral declivity described by Lesne (1932), nor does he mention the modifications of the female abdomen, nor the lateral pieces of the fifth abdominal ventrite of the male. 
The reasons for this are unknown. We believe that Lesne's (1932) original description is correct with regard to all these characters.

Following Lesne's (1932) description, the species possesses the antennal characters of Octomeristes gen. nov. rather than those of Octodesmus (Table 1), and the characters of the male and female abdomen are those of Octomeristes gen. nov. The sculpture of the elytral declivity with a pair of costae on the upper margin is closer to that of Om. pusillus gen. et sp. nov., than to the large declivital spines found in $\mathrm{Od}$. episternalis and Od. parvulus. Accordingly, we here transfer Od. minutissimus Lesne from Octodesmus to Octomeristes gen. nov.

Octomeristes minutissimus comb. nov. can be distinguished from Om. pusillus gen. et sp. nov. by the presence of two costae on each elytron and not three, and in the female by the presence of two long and thin spines in the middle of the posterior margin of the $4^{\text {th }}$ ventrite (Lesne 1932). The spines are much smaller and normally concealed by the $3^{\text {rd }}$ ventrite in the female of Om. pusillus gen. et sp. nov.

\section{Additional nomenclatural notes}

Octodesmus episternalis Lesne, 1901

Octodesmus episternalis Lesne, 1901: 618.

When he described the genus Octodesmus, Lesne (1901) did not designate a type species. Fisher (1950) designated Octodesmus episternalis Lesne as the type species. The name is based on a series of syntypes in several museums (Lesne 1901). The senior author has examined syntypes of the species in MNHN. Amongst them is a specimen labelled as lectotype by J.M.Vrydagh, but the designation was never published. In order to fix the identity of the species, we here designate this specimen as lectotype. It bears the labels: "Carin/Asciuli Cheba/1200-1300m/L. Fea I-88// $/ / /$ Octodesmus/episternalis Lesne/ type P. Lesne vid.// LECTOTYPE/J.M. Vrydagh". Both Lesne (1901) and Fisher (1950) note that this is the only known species of Bostrichidae in which the inner margin of the metepisternum is convex towards the ventral midline.

Xylion bifer Lesne, 1932: 659.

Paraxylion bifer (Lesne, 1932)

Octodesmus kamoli Chûjô, 1964: 209. syn. nov.

Paraxylion bifer - Lesne 1940: 150.

The senior author has examined syntypes of P. bifer (MNHN), and we have compared photographs of these with specimens collected in Thailand and Vietnam, and with the holotype, the only known specimen, of $O$. kamoli (KUM) collected in Thailand. The holotype of $O$. kamoli has lost the antennal club and the last two segments of the funicle on both sides, but there is no doubt that it is a specimen of $P$. bifer, which is a common species in Southeast Asia. Accordingly, we here synonymise $O$. kamoli with $P$. bifer.

\section{Key to genera and species of Xyloperthini with 8 antennomeres}

1. Antenna distinctly shorter than pronotum. Funicle subequal in length to first antennomere of club. Last antennomere with two distinct circular, sensory impressions. Elytral declivity with a large spine on each elytron. Female with unmodified third ventrite. Male without pleural pieces. (Octodesmus) (Od.)

- Antenna distinctly longer than pronotum. Funicle much shorter in length than first antennomere of club. Last antennomere without sensory impressions. Elytra with more than one costa, lacking 
LIU L.-Y. et al., A new genus of bostrichid beetle

spines on declivity. Female with third ventrite thickened and modified, overlapping and concealing fourth ventrite. Male with pleural pieces. (Octomeristes gen. nov.) $(O m$.$) .........................$

2. Anterior angles of pronotum without a marginal tooth. Area above anterior margin of pronotum finely rugose. Metathoracic episternum with its interior margin convex. Spines on elytral declivity marginal. Larger species, $3.2-5.5 \mathrm{~mm}$ long

Od. episternalis Lesne, 1901

- Anterior angles of pronotum with a marginal tooth. Area above anterior margin of pronotum smooth and shining. Metathoracic episternum with its interior margin straight. Spines on elytral declivity inserted inside the margins. Smaller species, $2.0-2.5 \mathrm{~mm}$ long

Od. parvulus (Lesne, 1897)

3. Elytra bicostate, the costae not convergent towards suture. Female fourth ventrite with a pair of long, thin spines in middle of posterior margin. Body reddish-brown with apical declivity darker. $1.8-2.5 \mathrm{~mm}$ long Om. minutissimus (Lesne, 1932) comb. nov.

- Elytra tricostate, the costae slightly convergent towards suture. Female with spines on fourth ventrite much smaller and concealed by $3^{\text {rd }}$ ventrite. Body pitchy-black. $1.9-2.1 \mathrm{~mm}$ long

Om. pusillus Liu \& Beaver, gen. et sp. nov.

\section{Discussion}

Park et al. (2015) have recently synonymised Calophagus Lesne, 1902 with Xylothrips Lesne, 1901. Hence, the description of Octomeristes gen. nov. keeps the number of genera in the tribe Xyloperthini at thirty-four (Borowski \& Węgrzynowicz 2007). The tribe has the most genera in the whole family, and often shows characters which are continuously variable amongst genera (Liu \& Schönitzer 2011). The tribe is greatly in need of revision and further phylogenetic analysis. Liu and Schönitzer (2011) suggest that the tribe is polyphyletic, but their study included only nine genera of Xyloperthini. A study including as many genera as possible is needed. The morphological distinctions between some of the genera are slight, and certain genera and species should possibly be synonymised (Liu, personal observations). The present geographical distribution of the tribe covers all zoogeographic regions except the Arctic-Siberian. Some genera are only distributed in limited areas, some are widely distributed, but the phylogeography of the genera remains unknown. The present paper is the first in a larger project which will try to resolve some of these problems.

\section{Acknowledgements}

We thank Dr. Toshiya Hirowatari and Dr. Satoshi Kamitani of Entomological Laboratory, Faculty of Agriculture, Kyushu University for the loan of the holotype of Octodesmus kamoli. Ms. Azadeh Taghavian was of great help when the senior author visited the Bostrichidae collection in MNHN, and later checked the Octodesmus collection for the type of O. minutissimus. We thank M. Sharkey (University of Kansas) and W. Srisuka (QSBG) for access to the specimens collected by the TIGER project, and the staff of the Thai National Parks who collected them. We are especially grateful to Dr. Rajesh Kumar, Central Muga Eri Research \& Training Institute in Assam, who very kindly took photographs of specimens of O. minutissimus in the National Pusa collection, New Delhi.

\section{References}

Beeson C.F.C. \& Bhatia B.M. 1937. On the biology of the Bostrychidae (Coleoptera). Indian Forest Records (new series) Entomology 2: 223-323.

Borowski J. \& Węgrzynowicz P. 2007. World catalogue of Bostrichidae (Coleoptera). Wydawnictwo Mantis, Olsztyn.

Chûjô M. 1964. Coleoptera from Southeast Asia (III). 17. Family Bostrichidae. Nature and Life in Southeast Asia 3: 201-215. 
Fisher W.S. 1950. A revision of the North American species of beetles belonging to the family Bostrichidae. Miscellaneous Publication 698. United States Department of Agriculture, Washington, D.C. http://dx.doi.org/10.5962/bhl.title.65663

Lesne P. 1901. Revision des Coléoptères de la famille des Bostrychides 4. Annales de la Société Entomologique de France 69: 473-639.

Lesne P. 1921. Classification des coléoptères xylophages de la famille des Bostrychides. Compte rendu de l'Association Française pour l'Avancement de Science, 44e Session, Strasbourg 1920: 285-289. http://www.biodiversitylibrary.org/item/27278\#page/289/mode/1up

Lesne P. 1932. Notes sur les Coléoptères Térédiles 22. Diagnoses de Bostrychides nouveaux de l'Asie orientale. Bulletin du Muséum national d'Histoire naturelle 1932: 651-663.

Lesne P. 1940. Sur quelques Bostrychides Indiens. Annales de la Société Entomologique de France 109: $137-152$.

Liu L.Y. \& Schönitzer K. 2011. Phylogenetic analysis of the family Bostrichidae auct. at suprageneric levels (Coleoptera: Bostrichidae). Mitteilungen der Münchner Entomologischen Gesellschaft 101: 99132.

Liu L.Y., Schönitzer K. \& Yang J. T. 2008. On the biology of Xylopsocus bicuspis Lesne, 1901 (Coleoptera: Bostrichidae). Mitteilungen der Münchner Entomologischen Gesellschaft 98: 5-12.

Park S., Lee S. \& Hong K-J. 2015. Review of the family Bostrichidae (Coleoptera) of Korea. Journal of Asia-Pacific Biodiversity 8 (4): 298-304. http://dx.doi.org/10.1016/j.japb.2015.10.015

Rai K. 1971. Studies on the morphology and taxonomy of Indian Bostrychidae (Coleoptera). XI. A revision of the Indian species of Octodesmus Lesne. Eos 46: 351-357.

Vrydagh J.M. 1955. Contribution à l'étude des Bostrychidae Coleoptera Teredilia 3. Les Bostrychidés de Mozambique. Bulletin de l'Institut Royal des Sciences Naturelles de Belgique 31 (16): 1-23.

Manuscript received: 16 November 2015

Manuscript accepted: 4 January 2016

Published on: 11 April 2016

Topic editor: Koen Martens

Desk editor: Kristiaan Hoedemakers

Printed versions of all papers are also deposited in the libraries of the institutes that are members of the EJT consortium: Muséum national d'Histoire naturelle, Paris, France; Botanic Garden Meise, Belgium; Royal Museum for Central Africa, Tervuren, Belgium; Natural History Museum, London, United Kingdom; Royal Belgian Institute of Natural Sciences, Brussels, Belgium; Natural History Museum of Denmark, Copenhagen, Denmark. 